\title{
Author Correction: Joule overheating poisons the fractional ac Josephson effect in topological Josephson junctions
}

Kévin Le Calvez, Louis Veyrat, Frédéric Gay, Philippe Plaindoux, Clemens B. Winkelmann, Hervé Courtois \& Benjamin Sacépé (1)

Correction to: Communications Physics https://doi.org/10.1038/s42005-018-0100-x, published online 8 January 2019.

The original version of this article contained an erroneous citation to Fig. $1 \mathrm{~b}$ in the third paragraph of subsection "Determination of the coherent transport regimes". The original version of the sentence "...as sketched in Fig. $1 \mathrm{~b}$ " should have been "....as sketched in Fig. 1a".

Also, in Fig. $3 \mathrm{~d}$ the two points marked by arrows in the $x$-axis have been erroneously labelled as "c" and " $d$ ". The correct labelling is "b" and "c".

These errors have been corrected in both the PDF and HTML versions of the article.

Published online: 16 June 2020

\footnotetext{
(c) (i) Open Access This article is licensed under a Creative Commons Attribution 4.0 International License, which permits use, sharing, adaptation, distribution and reproduction in any medium or format, as long as you give appropriate credit to the original author(s) and the source, provide a link to the Creative Commons license, and indicate if changes were made. The images or other third party material in this article are included in the article's Creative Commons license, unless indicated otherwise in a credit line to the material. If material is not included in the article's Creative Commons license and your intended use is not permitted by statutory regulation or exceeds the permitted use, you will need to obtain permission directly from the copyright holder. To view a copy of this license, visit http://creativecommons.org/licenses/by/4.0/.
}

(c) The Author(s) 2020 